\title{
Jugend und Religion in Österreich
}

\author{
Ilse Kögler / Maria Dammayr
}

The article Young People and Religion in Austria describes the complex relationship of young people to religious institutions and forms of faith. It considers the question of the importance religious expressions and practices may have for them. After the presentation of social and religious processes of transformation and their interpretation German test results are consulted and selected topics with the focal point Austria are discussed.

Ilse Kögler is Professor for Religious Pedagogy and Pedagogy and head of the Department of Catechetics and Religious Education at the Catholic University of Linz (KU Linz).

Maria Dammayr is DOC-Team-Fellow at the Institute of Sociology at the Johannes Kepler University Linz (JKU).

Die Jugendphase ist eine Zeit des Umbruchs, auch der Instabilität und der Fragilität - insgesamt ein Balanceakt zwischen Gelingen und Scheitern. In westeuropäischen Gesellschaften müssen Jugendliche ihre Identität auch innerhalb von Prozessen wie De-Institutionalisierung, De-Traditionalisierung, Pluralisierung und Individualisierung entwickeln und sich eigenverantwortlich verorten: Institutionen kontrollieren nicht mehr wie früher Verhalten und Einstellungen von Menschen; religiöse und kulturelle Traditionen büßen an Autorität für die individuelle Lebensgestaltung ein, und ihre Pluralisierung relativiert die religiöse und kulturelle Beheimatung. Von Jugendlichen wird erwartet, dass sie die individuelle Gestaltung ihrer Identität selbst in die Hand nehmen, und weil sie die „freie Wahl“" haben, liegt die Verantwortung für die jeweilige Wahl bei ihnen. ${ }^{1}$ Für den Soziologen Oevermann sind Biografien dadurch gekennzeichnet, dass sie in sozialem Handeln immer aufs Neue vor offene Entscheidungssituationen, Krisen gestellt werden, in denen sich der/die Einzelne zu bewähren hat, er/sie ein „Bewährungsproblem“ zu bearbeiten hat. ${ }^{2}$ Infolge der für die Jugendzeit auch typischen Ablösung von der vorangegangenen Generation entwickeln Jugendliche „eigene“ Antworten für ein gelungenes Leben. Dazu greifen sie Sinn- und Deutungsmuster nicht zuletzt aus einem ihnen bekannten, milieuspezifischen Repertoire auf, die ihnen Orientierung für ihr Handeln und für ihre Lebenspraxis bieten und welche dieses Handeln, diese Entscheidungen zudem zu legitimieren vermögen. Es sind vor allem existenzielle Fragen nach der eigenen Identität,

1 Vgl. Ziebertz / Hermans / Riegel 2010, S. 83-85.

2 Oevermann 2004. 
Herkunft und Zukunft, also Fragen im Hinblick auf die eigene Geburt und Sterblichkeit, auf ein zukünftiges sinnvolles Leben, mit Übergängen, Krisen und Grenzen, die sie nach „Bewährungsmythen“3 ${ }^{\text {‘3 }}$ suchen lassen, also nach Inhalten „nach denen sie ihr Leben gestalten wollen. Sie müssen herausfinden, was ihnen wichtig ist und woran sie sich als Individuen binden oder bewähren wollen." ${ }^{4}$

Es sind also die „Konstitutionsbedingungen der Lebenspraxis“, ${ }^{5}$ die der Bearbeitung bedürfen und die auf die Bedeutung von Religion abseits eines substanziellen und funktionalen Verständnisses hinweisen. Denn zur Bewältigung des „Bewährungsproblems“ bzw. der in Gang gekommenen „Bewährungsdynamik" besteht die Möglichkeit, sowohl auf Inhalte von Religion/en, aber auch auf profane, säkulare Deutungsmuster in ihren jeweils kulturspezifischen und historischen Varianten ,zuzugreifen“.

Im Folgenden wird der Blick zunächst auf allgemeine Prozesse gesellschaftlichen Wandels gelenkt, im Zuge dessen sowohl religiöse Organisationen, aber auch individuelle religiöse Praktiken, Sinn- und Deutungsmuster verändert und transformiert werden (1). Anschließend werden (ausgewählte) signifikante Untersuchungsergebnisse zur Religiosität Jugendlicher in Österreich vorgestellt, ergänzt und kommentiert durch solche aus den deutschsprachigen Nachbarländern (2).

\section{Religion im gesellschaftlichen Wandel}

In Österreich waren Religion und Glaube über viele Jahre rückgebunden an religiöse Gemeinschaften, von denen der katholischen Kirche eine unbestrittene Monopolstellung zukam. ${ }^{6}$ Sozialwissenschaftliche Forschungen belegen jedoch, dass in den Modernisierungsschüben der Sechziger- und Siebzigerjahre des 20. Jahrhunderts das mehr oder weniger geschlossene „katholische Milieu“ unumkehrbar zusammenbrach. ${ }^{7}$ Die Pluralität an Entwürfen der Lebensführung

\footnotetext{
3 Ebd.

4 Gärtner 2013, S. 214, vgl. auch 213 f.

5 Oevermann 2004.

6 Vgl. Bundeskanzleramt Österreich 2011, S. 9.

7 Vgl. Gabriel 1992, S. 52-68 und S. 124-146. Dies zeigt sich auch deutlich an den statistischen Daten zur religiösen Gesellschaftsstruktur Österreichs: Konnte die katholische Kirche vor etwa 50 Jahren noch eine Mitgliederzahl von 89 \% im Jahr 1961 aufweisen, war sie in den folgenden Jahrzehnten bereits von merkbaren Rückgängen betroffen, in denen ihre Mitglieder von 84,3\% im Jahr 1981 auf 64,3 \% im Jahr 2011 zurückgingen (Quellen: Für die Jahre 1961-2011: Statistik Austria 2007 und eigene Berechnungen;2011: Statistik Austria 2013a und eigene Berechnungen; Katholische Kirche Österreich o.J.). Der Rückgang der Mitglieder geht mit Auswirkungen auf die konfessionell gebundene religiöse Praxis einher, wie das Beispiel des sonntäglichen Gottesdienstbesuches veranschaulicht: Hier bestätigt sich die Rede vom schwindenden ka-
} 
und Weltdeutung, wie sie für moderne Gesellschaften kennzeichnend ist, kam sukzessive und unaufhaltsam auch im Alltag der Katholikinnen und Katholiken an. Als Kinder ihrer Zeit konnten sie sich mit vielem in der Kirche nicht mehr identifizieren. Die kirchlich Engagierten versuchten mit dem Rückenwind des 2. Vatikanischen Konzils (1962-1965) auf die Ordnungsgestalt der Kirche (Pflichtzölibat, Verbot der Frauenordination, Umgang mit wiederverheirateten Geschiedenen, Bischofsernennungen) und auf kirchliche Lehrentscheidungen (Sexualmoral, Ökumene) einzuwirken. Gleichzeitig wurde die Sozialform Kirche für immer mehr Menschen unbedeutend, und sie stellten sich ihre eigenen Muster der Lebensführung und der religiösen Weltwahrnehmung zusammen. Das ergab für die katholische Kirche in Österreich eine ungewohnte Situation: Plötzlich war sie der offenen Kritik sowohl einer allgemeinen gesellschaftlichen Öffentlichkeit ausgesetzt als auch der ihrer eigenen Mitglieder. Seit gut vierzig Jahren steht die Institution Kirche unter dem ,Zustimmungsvorbehalt ihrer Mitglieder“. 8

Damit steht die österreichische Kirche durchaus in einem breiteren Trend: Besonders in Europa gelten christliche Kirchen nicht mehr als selbstverständliche und unverlassbare Schicksalsgemeinschaften, sondern stellen eine von vielen möglichen AnbieterInnen auf dem „Markt“ von Lebensbewältigung, Wertevermittlung und Alltagsorientierung dar.

Dies bewog die soziologisch-wissenschaftliche Forschung zur Annahme eines zwangsläufig linear verlaufenden und durch Modernisierung bedingten Prozesses „der Trennung, der Herauslösung und Emanzipation praktisch aller Bereiche der menschlichen Lebenswelt vom Sinnkontext des christlichen Glaubens“.9 Die These der sogenannten Säkularisierung gilt es jedoch differenziert zu betrachten: So etwa unterscheidet Peter L. Berger diesen Prozess, „durch den Teile der Gesellschaft und Ausschnitte der Kultur aus der Herrschaft religiöser Institutionen und Symbole entlassen werden"10 in drei Dimensionen: (1) die gesellschaftlichinstitutionelle Dimension, die den Rückzug der Kirchen aus Bereichen früherer Einflussnahme beschreibt, (2) die kulturell-symbolische Dimension, welche vom Verschwinden religiöser Inhalte aus dem kulturellen Leben bei gleichzeitigem Anwachsen naturwissenschaftlicher Erkenntnisse ausgeht, und (3) eine subjek-

tholischen Milieu etwa darin, als dass im Jahr 2011 von den aktuell 64 \% KatholikInnen ca. $12 \%$ den sonntäglichen Gottesdienst besuchten (Katholische Kirche Österreich o. J.). Gleichzeitig zu dieser Entwicklung war die Anzahl der Menschen ohne Bekenntnis die am stärksten anwachsende Gruppe: Während etwa im Jahr 1951 3,8 \% konfessionslos lebten, ist diese Zahl im Jahr 2001 mittlerweile auf 12 \% gestiegen (Quelle: Statistik Austria 2007 und eigene Berechnungen).

8 Vgl. Bucher 2005, S. 17-19.

9 Figl 2005, S. 74

10 Vgl. Berger 1973, S. 103. 
tive Dimension, bei der Säkularisierung zusehends auch im Bewusstsein von immer mehr Menschen ankommt, die sodann ohne Religion auskommen. ${ }^{11}$

Heute ist man mit eindeutigen Diagnosen ,zurückhaltender“, da sich beobachten lässt, dass Religion trotz fortschreitender Modernisierung weder auf allen diesen drei Ebenen gleichermaßen verschwunden ist, noch dass Religion als solche obsolet geworden wäre. ${ }^{12}$ Insofern diese Differenzierung auch mit methodischen Ausweitungen (etwa des Religionsbegriffes) einhergeht, ist in der religionssoziologischen Debatte seit mehreren Jahren eine Kontroverse über eine „fortschreitende Säkularisierung“ einerseits und eine „Rückkehr des Religiösen“ andererseits entbrannt. ${ }^{13}$ Die Rede von einer Rückkehr des Religiösen wurde besonders durch die Annahme von Privatisierungs- und Individualisierungstendenzen, wie sie besonders Thomas Luckmann in die Diskussion einbrachte, prominent. Die These einer zunehmenden „Individualisierung von Religion“ geht davon aus, dass individuelle und soziale Funktionen von Religion, wie z. B. Kontingenzbewältigung und Gemeinschaftsfundierung, nicht mehr notwendig an institutionalisierte Religionsgemeinschaften gebunden sind, sondern von einer Vielfalt konkurrierender Sinnangebote auch außerhalb der Kirchen bedient werden. Das souveräne Selbst als prinzipielle Autorität des wiederbelebten Glaubens wählt aus dieser Vielfalt aus. Ulrich Beck sieht eine durch die Säkularisierung eingeleitete Entkoppelung von Religion und Religiosität, wobei er unter Religion die institutionelle Dimension (Kirche) versteht und unter Religiosität die Dimension des persönlichen Glaubens. ${ }^{14}$ Im Zuge dieser Entwicklungen kommt es immer mehr zum Bedeutungsverlust kirchlicher Religiosität bzw. ihrer institutionellen Formen. ${ }^{15}$

11 Vgl. ebd., S. 103.

12 In dieser Hinsicht ist es zudem nicht unwesentlich, in welchem geografischen Raum und kulturellen Kontext die Frage nach der Religion gestellt wird. Weltweit betrachtet kann weder von einem Rückgang noch von einem Verschwinden der Religion gesprochen werden, vielmehr nimmt im außereuropäischen Raum die Zahl der Menschen zu, die sich zu religiösen Gemeinschaften zählen, religiöse Überzeugungen haben und religiöse Praktiken vollziehen. Dabei beschränkt sich die religiöse Vitalität nicht auf ökonomisch schlechter gestellte Länder und Krisenregionen, sondern ist auch in hochentwickelten Gesellschaften der Vereinigten Staaten und in wirtschaftlich aufstrebenden Ländern Asiens vorzufinden. Zunehmend gerät Westeuropa in Sachen Religion in eine Sonderrolle. Die hier vorherrschende Praxis einer Zurückdrängung der Religion in die Privatsphäre findet keine globale Verbreitung (vgl. Gabriel 2013; Casanova 1994, 2007).

13 Gärtner 2013, S. 212.

14 Beck 2012, S. 230.

15 Diese Annahme muss allerdings differenziert betrachtet werden, insofern auch Mitglieder der Kirchen Angebote aus anderen Religionen (z. B. Yoga, Mandala-Malen) oder aus dem esoterischen Spektrum bzw. einer New-Age-Spiritualität aufgreifen. Dadurch kommt es zwar zu einer Divergenz von formaler und faktischer Religiosität, aus theologischer Sicht zu einer ,Erosion“ kirchengebundener Religiosität, dennoch muss 
KritikerInnen dieser These halten dem entgegen, dass dieser Auffassung meist ein sehr weiter und funktionaler Begriff von Religion zu Grunde gelegt wird, der etwa auch Sozialisierung und die Personwerdung des Menschen als ein religiöses Phänomen beschreibt. ${ }^{16}$ Eine solche „Ausweitung des Religionsbegriffes“ schließe demnach „Säkularisierung“ bereits auf begrifflicher Ebene aus. Damit blieben vorhandene Säkularisierungsprozesse unbeachtet ebenso wie die Tatsache, dass etliche europäische Länder zutiefst und auf eine je besondere Art säkular bzw. säkularisiert sind. ${ }^{17}$ Insgesamt lässt sich jedoch festhalten, dass die Auffassung, wonach Modernisierung notwendig zur Säkularisierung führt, heute seltener vertreten wird, sondern alternative Deutungen für den religiösen Wandel gesucht werden. Zudem wird davon ausgegangen, „dass die Säkularisierung in Europa nie ein linearer, kontinuierlicher und einheitlicher Prozess war, sondern dass wir es mit einer hochgradig konfliktdurchsetzten, heterogenen und kontingenten Geschichte zu tun haben“. 18

Der gesellschaftliche und religiöse Wandel lässt also das Christentum nicht abhandenkommen, schwächt aber institutionelle Bindungen, individualisiert und pluralisiert seine Sinngehalte und Erscheinungsformen. Unstrittig ist in der europäischen religionssoziologischen Debatte der empirische Befund einer seit den 1960er-Jahren kontinuierlich sinkenden kirchlich gebundenen Religiosität und Praxis. In westeuropäischen Gesellschaften lassen sich einander widerstreitende Entwicklungen und empirische Belege finden: einerseits ein enormer Bedeutungsverlust religiöser Überzeugungen im Ensemble der kollektiven und individuellen Lebensführungsgewissheiten, andererseits ein Fortbestehen religiöser Traditionen, welche nicht bloß auf eine fundamentalistische Selbstverhärtung oder eine sozio-kulturelle Verdrängung zu reduzieren sind. Zudem begegnen religiöse Versatzstücke vermehrt in säkularen Kontexten, wie z. B. bei sportlichen Großveranstaltungen, in Präsentationsformen der Popkultur oder in der Mischung von Heil und Heilung auf dem Gesundheitsmarkt. ${ }^{19}$

Parallel zu diesen Phänomenen nehmen heute Kirchen Formen der populären Kultur auf, um den gesellschaftlichen Entwicklungen entsprechen zu können und einem weiteren Verlust an Kirchenmitgliedern durch „,bedürfnisorientierte Angebote" entgegenzuwirken. Dies zeigt sich im Einsatz einer popkulturellen Medienlogik (Weltjugendtage, evangelische Kirchentage) und einer Eventisierung traditioneller Religion. Situative Event-Gemeinschaften sind auf das inszenierte

eine individualisierte Religiosität nicht zwangsläufig eine Alternative zur Religionsmitgliedschaft darstellen (vgl. Gründer / Scherr 2012, S. 68-69). Festgehalten wird auch, dass sich Individualisierung vor allem in den Kirchen und Religionsgemeinschaften abspielt (Verhülsdonk 2012, S. 21).

16 Vgl. Pollack 2003.

17 Vgl. Joas 2012 S. 69f.

18 Ebd., S. 68.

19 Vgl. Höhn 2013, S. 58-62. 
Massenspektakel beschränkt. In ihnen geht es vor allem um eine Stärkung der Corporate Identity: „Die gelebte Vielfalt des Katholischen sollte für einen herausragenden Moment - oder um mit Max Weber zu sprechen: für einen ,charismatischen' Augenblick - als große, widerspruchslose Einheit nach außen präsentiert und für die Teilnehmer erlebbar gemacht werden." ${ }^{\text {20 }}$

Als neue Sozialform des Religiösen wird in einer pluralen Welt die individuelle Suche nach Spiritualität gesehen, deren Kern besondere Erfahrungen der Transzendenz bildet: Wandern auf dem Jakobsweg, Feng-Shui, Engelskult, um nur einige Beispiele zu nennen, sollen diese ermöglichen. Die alten Grenzen von sakral und heilig werden aufgelöst, der gesellschaftliche Hintergrund ist der Mensch als selbstbestimmtes Individuum und seine Suche nach Sinn, Beheimatung, Heil(ung) und Glück. ${ }^{21}$

Die britische Religionssoziologin Grace Davie diagnostizierte daher den Zustand der europäischen religiösen Gegenwartskultur mit „Believing without Belonging“, Glauben ohne Zugehörigkeit, ${ }^{22}$ womit sie ausdrückt, dass religiöse Praxis und Religionszugehörigkeit entkoppelt werden. Die vormals dominante sozialintegrative Funktion der Religion tritt hinter ihre biografieintegrative Funktion zurück. ${ }^{23}$ Mit der Privatisierung und Individualisierung von Religion verschwindet hingegen für den deutschen Soziologen Winfried Gebhardt weder das Bedürfnis nach Zugehörigkeit und Gemeinschaftserfahrungen, noch die Suche nach Autorität und Führung. Selbst Kirchenmitgliedschaften werden dadurch nicht beendet, allerdings neu definiert. Er flankiert daher Davies Befund mit zwei ergänzenden Aussagen: „Belonging without Obeying“, dazugehören ohne zu gehorchen, und/oder „Belonging without Commitment“, dazugehören ohne Verpflichtung, zugespitzt in der Aussage: „Was gut katholisch oder evangelisch ist, bestimme ich selbst “. ${ }^{24}$ Oftmals gerät aus dem Blick, dass im Christentum wie in anderen Religionen Menschen auf individuelle Art unterschiedliche Ausprägungen ihres ,verfassten“ Glaubens leben. Deshalb sind Religionen auch weniger als abstrakte Lehren zu sehen, sondern als dynamische Lebensorientierungen von Menschen und ihren Gemeinschaften.

Im Zusammenhang mit dem Prozess religiöser Individualisierung und dem Umstand, dass nunmehr aus der Vielfalt spiritueller Angebote solche ausgewählt werden, die helfen sollen, das Leben zu meistern, sind die Begriffe Patchworkreligion („Fleckerlteppichreligion“) oder Bricolage („Bastelreligion“) zu erwähnen. Diese sind jedoch kritisch daraufhin zu prüfen, ob sie das im Durch-

20 Forschungskonsortium WJT 2007, S. 214.

21 Vgl. Knoblauch 2009.

22 Davie 1994, S. 94. Davie beschränkt sich in ihren Überlegungen im Wesentlichen auf die christliche Religion.

23 Vgl. Höhn 2013, S. 67.

24 Gebhardt 2013, S. 299. 
schnitt ausgeschöpfte Spektrum religiöser Optionen nicht überschätzen. ${ }^{25}$ Denn blickt man z. B. in den Bertelsmann-Religionsmonitor (2007), bilden nach wie vor die Kirchen und Religionsgemeinschaften „den sozialen Rahmen, in dem sich die Bildung religiöser Identitäten vollzieht, und sei es in Abgrenzung und Dissens“ “. ${ }^{26}$ Zumindest bis heute führt religiöse Pluralität „nicht zu der eigentlich erwartbaren Zahl von Konversionen, eigenständigen Synkretismen und substantiell neuen religiösen Referenzsystemen“. ${ }^{27}$

Schließlich hat sich der gesellschaftliche Kontext in den letzten Jahrzehnten zudem durch Globalisierung und Migration deutlich verändert. Migration geht mit Wandlungsprozessen einher, trägt zur Vielfalt von (religiösen) Sinnangeboten, Perspektiven und Weltanschauungen bei und lenkt gleichzeitig das Augenmerk auf das Bestehende und Bekannte. Jugendliche kommen selbstverständlich in Kontakt mit anderen kulturellen und religiösen Traditionen, werden durch sie auch in ihren eigenen religiösen Vorstellungen angefragt bzw. diese können dadurch relativiert werden. Vor allem durch den Islam hat Religion einen sichtbaren (Bedeutungs-)Zuwachs erfahren, ${ }^{28}$ so auch in der österreichischen Öffentlichkeit. $^{29}$

\section{Untersuchungsergebnisse zur Religiosität Jugendlicher in Österreich}

Wer sich aus wissenschaftlichem Interesse der Erforschung von Religion/en, dem religiösen Verhalten und den unterschiedlichen Glaubens- und Spiritualitätsformen widmet, merkt rasch, dass es sich dabei um kein einfaches Unterfangen handelt, denn „Wer über Religion redet, bewegt sich auf Glatteis. Allein die Versuche, den Gegenstand zu bestimmen, sind zahllos. “30 Der Sozialwissenschaftler Andreas Feige stellt daher die berechtigte Frage, mittels welcher

\footnotetext{
25 Vgl. Englert 2012, S. 176.

26 Verhülsdonk 2012, S. 21.

27 Vgl. Englert 2012, S. 176.

28 Gärtner 2013, S. 216.
}

29 Im Jahr 2012 lebten 1.578,900 (18,9 \% ) Menschen mit Migrationshintergrund in Österreich (Quelle: Statistik Austria 2013b).

Im Hinblick auf Religion ist die islamische Religionsgemeinschaft auch in Österreich als am stärksten anwachsend und religiös durchaus vital zu verzeichnen: Waren im Jahr 1971 $0,3 \%$ der muslimischen Religion zugehörig, so hat sich das bis 2001 auf 4,2 \% gesteigert (Statistik Austria 2007 und eigene Berechnungen) und beläuft sich ihre Mitgliederzahl einer Hochrechnung des Forschungsprojekts „Muslimische Milieus in Österreich“ zufolge im Jahr 2012 auf 6,6 \%, das sind 573,876 Mitglieder (vgl. Kizilkaya / El Hadad 2012, S. 17). Somit ist die muslimische Glaubensgemeinschaft die zweitgrößte nach den KatholikInnen.

30 Knoblauch 2009, S. 43. 
Theorien und Erschließungstechniken in der Jugendforschung „realitätsnahe“ Einsichten zum Thema „Religiosität" gewonnen werden sollten. ${ }^{31}$ In empirischen Jugendstudien zur Untersuchung der Religiosität Jugendlicher wird holzschnittartig zugespitzt primär eine substanzielle, eine funktionale und eine diskursive Bestimmung von Religion unterschieden. ${ }^{32}$ In den Forschungen mit substanziellem Ansatz ${ }^{33}$ werden vor allem Zustimmungen zu etablierten Glaubensvorstellungen erhoben und Praktiken von Religion erfragt. Zudem werden nicht selten die phänomenologisch ausgerichteten Glock'schen Dimensionen der Religiosität $^{34}$ als Grundlage für die Erstellung von Forschungsfragen herangezogen (in Österreich z. B. Khorchide 2007). Für die Forschung mit einem funktionalen Religionsbegriff stehen die Leistungen von Religion für Mensch und Gesellschaft im Vordergrund, welche auf dem Hintergrund idealiter gedachter Funktionen von Religion reflektiert werden. ${ }^{35}$ Forschungen mit diskursivem Ansatz ${ }^{36}$ folgen Joachim Matthes' „Vorschlag, ,Religion“ und ,Religiosität“ als diskursive Tatbestände zu betrachten - als Tatbestände also, die sich im gesellschaftlichen Diskurs konstituieren ". ${ }^{37}$ Sie wollen deutlich machen, dass Jugendliche, welche explizit religiöse Semantiken kaum noch gutheißen oder deren religiöse Deutungspotenziale nicht ausreichend durch jene Items repräsentiert werden, die im Forschungsvollzug je konkret vorgegeben werden, deshalb nicht bereits nicht-religiös

31 Feige 2012, S. 95; Vgl. im Folgenden auch Kögler 2014.

32 Vgl. Streib / Gennerich 2011, S. 13-17; Kögler 2014.

33 Deutsche Shell 2006 und 2010; Österreichische Jugendwertestudien 1990-2006; Jugendwerte-Studie 2011.

34 Charles Y. Glock hat gemeinsam mit Rodney Stark religionsphänomenologisch fünf Kerndimensionen der Religiosität unterschieden, die in allen Religionen anzutreffen seien: eine ideologische (Glaubenssätze), eine ritualistische, eine erfahrungsmäßige, welche das subjektive religiöse Erleben meint, eine intellektuelle (Wissen um Glaubensinhalte) und eine auf Konsequenzen bezogene, in der es um Auswirkungen des Glaubens im Alltagsleben geht (vgl. Figl 2003, S. 70).

35 Kaufmann 1989; Barz 1992/93.

36 Feige / Gennerich 2008; Husmann 2008; Streib / Gennerich 2011.

37 Matthes 1992, S. 129. Matthes weist in seiner Argumentation gegen die Verwendung von „Religion“ als einem Begriff, der „über definitorische Bemühungen zu ,fassen“ ist" (Matthes 1992, S. 131) nach, dass sowohl TheologInnen wie auch SoziologInnen in den je eigenen - persönlichen wie gesellschaftlichen - Verstrickungen mit Religion befangen sind. Beide würden Religion und Religiöses in Abgrenzung von etwas verstehen. Weil sie ihre eigene Beteiligung an dieser Abgrenzung nicht reflektierten, könnten sie Religion und Religiöses nicht als etwas sehen, ,das unseren heutigen Lebensbedingungen gleichsam ,natürlich' sein könnte. Und mehr noch: beide haben ihre je eigenen Schwierigkeiten damit, ihre jeweilige Rolle mitzudenken, die sie in jenem Zusammenhang spielen, in dem das Religiöse auch im Alltagsleben als etwas eher Absonderliches erscheint" (ebd., S. 137). 
sind. Sie zeigen Anschlussstellen für Kommunikation, können aber keinen „Religiositäts-Status“ ermitteln.

\section{1. Österreichische Jugend-Wertestudie 1990-2006 und Jugend-Wertestudie 2011}

Die Österreichische Jugend-Wertestudie 1990-2006 ${ }^{38}$ arbeitet im Anschluss an die Europäische Wertestudie ${ }^{39}$ seit 1990 weitgehend mit einem traditionellen, substanziellen Religiositätskonzept, welches ,,stark christlich geprägt ist und den Glauben an Gott, kognitive Lebensdeutungen sowie rituelle und liturgische Praxis als wesentliche Elemente von Religiosität versteht" ${ }^{40}$ Ebenfalls folgt die Jugend-Wertestudie 2011 in ihrem quantitativen Teil einem substanziellen Religionsbegriff. $^{41}$

\subsubsection{Wandel konfessioneller Religiosität}

Die österreichischen Jugend-Wertestudien 1990-2006 ermöglichen in Bezug auf die Religiosität Jugendlicher einen Ein- wie Überblick hinsichtlich des religiösen Wandels in einem Land, das mehrheitlich kirchlich (katholisch) geprägt war und in dem konfessionelle wie religiöse Pluralität weitgehend nicht wahrgenommen wurden. Sie zeigen, dass die sozioreligiöse Dominanz einer bestimmten religiösen Lebensweise zu Ende geht, Individualismus wie Pluralismus auch in Österreich der Normalfall sind. Die Religiosität bei jungen Menschen ist im Umbruch, ambivalent und vieldeutig. ${ }^{42}$

38 Sie ist ein Langzeitprojekt, in dem sowohl quantitative als auch qualitative Untersuchungsmethoden (Fokusgruppen) zur Anwendung kommen. Globalziel der Studie ist die Untersuchung von Lebenskonzepten und Werthaltungen junger ÖsterreicherInnen. 1990 und 2000 wurden Jugendliche zwischen 16 und 24 Jahren befragt, 2006/2007 Jugendliche zwischen 14 und 24 Jahren, darunter auch erstmals Jugendliche mit Migrationshintergrund - nicht-muslimische wie muslimische Jugendliche der ersten und zweiten Generation. Publiziert sind die Ergebnisse der drei Untersuchungswellen in Friesl (Hg.) 2001 und Friesl / Kromer / Polak (Hg.) 2008.

39 Vgl. Denz 2002.

40 Polak 2008, S. 133.

41 Die Jugend-Wertestudie 2011 arbeitet auf Basis einer Methodentriangulation mit Gruppendiskussionen, einer repräsentativen quantitativen Untersuchung und qualitativen Einzelinterviews. Erhebungsgruppe sind 14- bis 29-jährige junge ÖsterreicherInnen, wobei zwischen Jugendlichen (im Alter von 14 bis 19 Jahren) und jungen Erwachsenen (im Alter von 20 bis 29 Jahren) unterschieden wird. Die Schwerpunktthemen sind weltanschauliche Orientierungen, gesellschaftspolitische Positionen, Wahrnehmungen des sozialen Zusammenhalts sowie Ausbildung und Arbeitswelt. Heinzlmaier / Ikrath 2012.

Vgl. Polak 2008, S. 133. 
Die Daten der Jugend-Wertestudie 2011 bestärken die Daten hinsichtlich einer fortschreitenden Erosion traditionell religiöser Sinnhorizonte. Es sinkt der Anteil jener jungen Menschen, die einer Religionsgemeinschaft angehören. Während 1990 noch 91 \% in der Vergleichsgruppe der 16- bis 24-Jährigen konfessionell gebunden waren, sank dieser Teil im Jahr 2000 auf 82 \%, im Jahr 2006 auf 80 \% und weiter auf $72 \%$ im Jahr $2011 .^{43}$

Die Daten einer empirischen Untersuchung zu Weltbildern von 16- bis 18jährigen Jugendlichen in Deutschland zeigen keinen totalen Auszug Jugendlicher aus den Kirchen, allerdings lassen sich in den Antworten zu religiöser Praxis nur Spurenelemente kirchlich gestützter Religiosität finden. ${ }^{44}$ Neuere Milieu-Theorien, wie die Sinus-Milieus, ${ }^{45}$ bestätigen ebenfalls den Rückgang der institutionellen Bindungen Jugendlicher und machen gleichzeitig ihre milieuunterschiedlichen Einstellungen zu Kirche und Glaubensgemeinschaften anschaulich. So muss auch eine sehr kritische Haltung zur Kirche nicht zwingend die Überlegung folgen lassen, aus dieser Institution (später) auf jeden Fall auszutreten. Für bedeutsame Stationen in der Normalbiografie, wie z. B. Hochzeiten, Taufen, weihnachtlicher Kirchbesuch mit den Kindern, wird sie als „Ankerpunkt“ oder „Dienstleister“ geschätzt. ${ }^{46}$

\subsubsection{Religiöses Selbstverständnis}

Ein markantes wie widersprüchliches Ergebnis der Studie 1990-2006 ist, dass das religiöse Selbstverständnis und die Zustimmung zum Glauben an Gott immer weiter auseinanderklaffen. Bereits 1990 zeichnete sich ab, dass 14- bis 24-jährige junge Menschen nicht mehr in einem traditionell-kirchlich (konfessionellen) Sinn religiös sind. ${ }^{47}$ In der Replikationsstudie 2006 wird ihnen eine ,gottesfreundliche Religionslosigkeit“ bescheinigt. Der Satz „Ich glaube an Gott, bin aber nicht religiös“ bringt die Spannung zwischen der niedrigen Zustimmung zu einem religiösen Selbstverständnis einerseits (34 \%) und einer 2006 vergleichsweise hohen Zustimmung zu einem Glauben an Gott (69\%) zum Ausdruck. Während sich 1990 noch 52 \% der 16- bis 24-jährigen Jugendlichen als religiös bezeichneten und $62 \%$ angaben, an Gott zu glauben, sank 2000 die religiöse Selbsteinschätzung auf $42 \%$ und der Gottesglaube auf $50 \%{ }^{48}$ Allerdings korreliert 2006 nur bei einer Minderheit die hohe Zustimmung zu einem Glauben an Gott mit explizit religiösen Praxisformen, wie z. B. beten, meditieren, religiöse Feiern besuchen, sodass unklar bleibt, was diese praktisch bedeutet. ${ }^{49}$

43 Vgl. Heinzlmaier / Ikrath 2012, S. 39; Polak 2008, S. 144.

44 Ziebertz / Riegel 2008, S. 154.

45 Z. B. Calmbach u. a. 2012.

46 Vgl. ebd., S. 167; S. 244; S. 318.

47 Vgl. Polak 2008, S. 129.

48 Vgl. ebd., S. 140-141.

49 Vgl. ebd., S. 162-165. 
In der Jugend-Wertestudie 2011 verorten Befragte die Stärke ihres eigenen religiösen Empfindens auf einer Skala von 1 (überhaupt nicht religiös) bis 10 (sehr religiös). Der Blick auf die beiden Extremwerte zeigt, dass sich rund $22 \%$ der hier 14- bis 29-jährigen jungen ÖsterreicherInnen als , überhaupt nicht religiös“ und nur rund $3 \%$ als ,sehr religiös“ bezeichnen. $28 \%$ empfinden sich (tendenziell) religiös (Skalenpunkte 6 bis 10) und $72 \%$ als (tendenziell) weniger religiös (Skalenpunkte 1 bis 5). Frauen verstehen sich religiöser als Männer, ordnen zu 32 \% die Stärke ihres religiösen Empfindens bei einem Wert von 6 und höher ein, Männer zu 24 \%. Ebenso geben $46 \%$ der Jugendlichen und jungen Erwachsene mit Migrationshintergrund die Skalenpunkte 6 bis 10 an, jene ohne Migrationshintergrund nur zu $25 \% .{ }^{50}$ Mitbedacht werden muss, dass in Befragungen Jugendliche mit dem Begriff „religiös“ oft eine traditionelle, meist kirchlich praktizierte Form von Religiosität assoziieren bzw. denken, dass ihre InterviewerInnen das mit dieser Frage verbinden.

In den statistischen Daten von 2011 zeigt sich, dass Jugendliche, die an einen „leibhaftigen Gott“ glauben, sich religiöser empfinden als diejenigen, die an ,ein höheres Wesen oder eine geistige Macht glauben“. Die Jugendforscher schließen auf einen nach wie vor starken Zusammenhang zwischen religiöser Selbsteinschätzung und monotheistischen Glaubensinhalten. ${ }^{51} \mathrm{Ob}$ die ,leibhaftige“ Gottesvorstellung eine monotheistische ist, also auf jene der jüdischen, christlichen oder muslimischen Glaubenstradition zurückgreift, lässt sich u. E. hier nicht einfach herauslesen. So diagnostiziert z. B. Ulrich Beck einen Wandel der Religiosität, deren Kern es ist, einen eigenen Gott zu haben, der für andere unplausibel sein mag, für das Individuum selbst aber unüberbietbare Richtschnur ist. Oft sei das nicht der Gott der Kirchen, Synagogen, Moscheen und Tempel, sondern der Gott der eigenen Erfahrung. Der Einzelne könne einen absoluten Gott schaffen und bleibe auch Autorität des wiederbelebten Glaubens. ${ }^{52}$

\subsubsection{Gottesbild}

Die Frage nach Gott wird in allen österreichischen Jugend-Wertestudien gestellt, allerdings wird eine Ablehnung der Person-Semantik nicht als so rigoros interpretiert wie in den deutschen Shell-Jugendstudien 2006 und 2010 (vgl. Kapitel 2).

Der Datenvergleich der insgesamt vier Befragungen (1990, 2000, 2006 und 2011) zeigt, dass der Anteil der 16- bis 24-jährigen jungen Menschen, die an einen leibhaftigen/persönlichen Gott glauben relativ stabil geblieben ist. 1990 und 2011 wurde mit dem Item ,es gibt einen leibhaftigen Gott“ gefragt, 2000 und 2006 mit dem Item ,es gibt einen persönlichen Gott“. Dadurch ist die Vergleichbarkeit der Daten nicht vollständig gewährleistet.

\footnotetext{
50 Vgl. Heinzlmaier / Ikrath 2012, S. 39f.

51 Vgl. ebd., S. 42.

52 Vgl. Beck 2008; siehe auch Demont / Schenker 2009.
} 


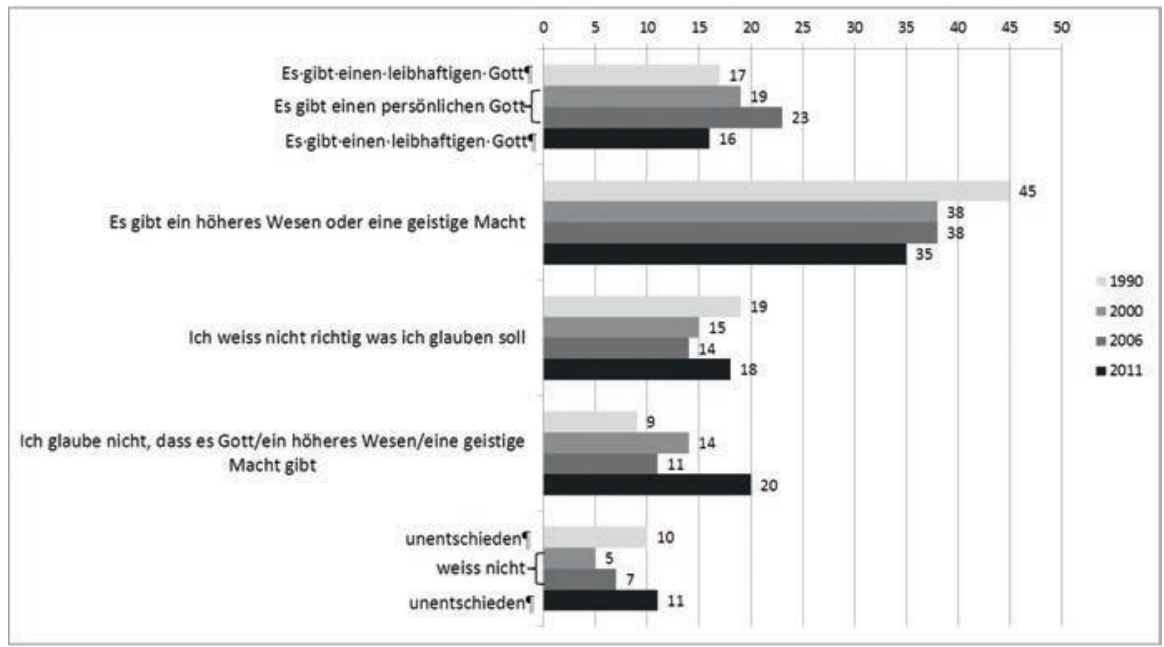

Graphik 1: Angaben in \%; Quellen: Jugend-Wertestudie $1990(\mathrm{n}=750)$; Jugend-Wertestudie $2000(\mathrm{n}=816)$; Jugend-Wertestudie 2006/07 $(\mathrm{n}=1001)$ aus: Friesl / Kromer / Polak 2008, S. 156; Heinzlmaier / Ikrath: Jugend-Wertestudie $2011(\mathrm{n}=838)$, aus: Heinzlmaier / Ikrath 2012, S. 41.

\subsubsection{Was kommt deiner Überzeugung am nächsten?}

Als „überwiegend recht diffus“ werden Glaubensinhalte junger ÖsterreicherInnen in der Jugend-Wertestudie 2011 bewertet. In den Gruppendiskussionen ist der Glaube an eine „höhere Macht“ am weitesten verbreitet. Deren Hauptaufgabe besteht vor allem darin, „Trost zu spenden und den Gläubigen ein Gefühl der Geborgenheit zu geben, nicht aber, deren Selbstverwirklichungsansprüchen durch spezifische Forderungen nach einer tugendhaften Lebensführung im Wege zu stehen “. ${ }^{53}$ Auch in einer Schweizer Jugendstudie ${ }^{54}$ steht ein nicht näher bestimmbarer Glaube an eine höhere Macht, ohne Dogmen und Bekenntnisse, im Zentrum einer „Sozial tolerierten Minimumreligion“.55 Zur verbreiteten Denkfigur wurde die Vorstellung, sich bewusst Gott selbst zu schaffen, um das Leben besser bewältigen zu können. „Minimumreligion“ ist eine ganz diesseitige, beeinflusst nicht den ethischen Entscheid, sondern soll Gelassenheit und Halt vermitteln, Konsum oder Lebensgestaltung aber nicht einschränken. Ihre Hauptfunktion ist die Deutung des Unvorhersagbaren, weil das hereinbrechende Unerklärliche erklärt werden will.

53 Heinzlmaier / Ikrath 2012, S. 40.

54 Vgl. Demont / Schenker 2009.

55 Ebd., S. 193. 
„Mit anderen Worten: Religion ist die Antwort auf die,Warum-gerade-ich-Frage“ mit dem Rückgriff auf eine übernatürliche Wirklichkeit. “" ${ }^{\text {(6) }}$

\subsubsection{Alternativ-religiöse Praktiken, Spiritualität und ,Feminisierung von Religion"*}

Alternativ-religiöse (,esoterische“) Praktiken wie beispielsweise Tarotkarten legen oder Astrologie ersetzen traditionelle Religiosität nicht und gelten als ein Minderheitenphänomen. ${ }^{57}$ Hinsichtlich des skizzierten Wandels von Religiosität wird in religionssoziologischen Studien ein Ansteigen des Phänomens der Spiritualität dokumentiert. Es scheint heute eine gesellschaftlich stärker akzeptierte Haltung zu sein, sich zu einer eigenen Spiritualität zu bekennen, als sich als religiöser Mensch zu bezeichnen. Formen einer „de-institutionalisierten“ Spiritualität sollten ebenfalls nicht überbewertet werden. Streib und Gennerich nehmen an, dass sich etwa jeder achte Jugendliche eher mit „Spiritualität“ identifiziert als mit Religion oder säkularer Identität. Hierbei sei eine noch offene Frage, ob nicht Spiritualität für viele Jugendliche eine Art Wahl des kleineren Übels ist, weil sie sich mit einer institutionalisierten Religion nicht mehr identifizieren können. Jedenfalls können Jugendliche auf die Kategorie eines Letzthorizontes zurückgreifen, um Erfahrungen $\mathrm{zu}$ interpretieren, sodass sie mit dem Matthes'schen Religionsbegriff wissenschaftlich als religiös beschrieben werden können, ohne dass sie ein unkritischbejahendes Verhältnis zum Begriff „Gott“ haben. ${ }^{58}$ Bereits in der österreichischen Jugend-Wertestudie von 2006 lassen sich ähnliche Entwicklungen erkennen: Zwar bezeichnen sich nur $4 \%$ der Befragten als spirituell, jedoch geben weitere $11 \%$ an, sich bereits selbst damit beschäftigt zu haben, und weitere $25 \%$ zeigen für das Thema Interesse; lediglich 11 \% kennen den Begriff Spiritualität nicht. ${ }^{59}$ Jenen, die Affinitäten zu Spiritualität haben, bedeutet diese ,eine Form der Selbsterfahrung (42\%), die dazu verhelfen kann, Glück und Sinn im Leben zu finden (30\%) und das Geheimnis des Lebens zu entdecken (34 \%). Spiritualität gilt für $30 \%$ als eine moderne Art religiös zu sein (30 \%). Heilung (17 \%) und Orientierung im Leben $(19 \%)$ sind weniger relevante Dimensionen, ebenso wenig die Gemeinschaft $(15 \%)^{*} \cdot 60$

Besonders im Hinblick auf das Phänomen Spiritualität lohnt eine differenzierte Betrachtung mit dem religionssoziologischen Befund einer „Feminisierung von Religion“".61 Wenn in empirischen Untersuchungen zwar nicht bei allen Themen Geschlechterungleichheiten festzustellen sind, so zeigen sie sich unter anderem in der Selbstzuschreibung von Religiosität. Diese scheint mehr eine

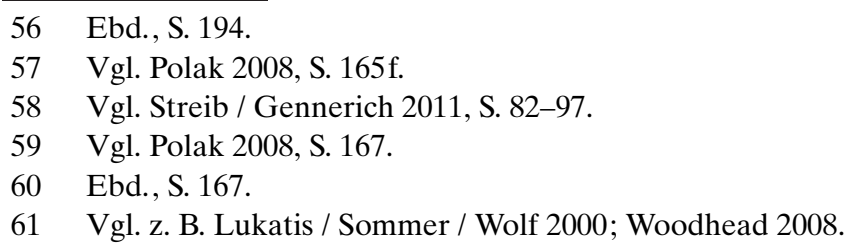


Angelegenheit junger Mädchen und Frauen zu sein, die sich selbst eher als religiös bezeichnen, denn männlicher Jugendlicher. Diese wiederum dominieren bei der Angabe, dass Religion „überhaupt nicht wichtig“ ist. ${ }^{62}$ Die Relevanz alltagspraktisch gelebter Religiosität ist ebenfalls tendenziell weiblich. ${ }^{63}$

Hinsichtlich der Geschlechterdifferenz zeigt sich in der österreichischen Jugend-Wertestudie 2006, dass junge Mädchen und Frauen an Themen der Spiritualität und Esoterik ein deutlich ausgeprägteres Interesse haben als junge Burschen und Männer. ${ }^{64}$

Widersprüchlichkeiten in der gesamten Datenlage weisen allerdings darauf hin, dass Geschlechtsspezifika so eindeutig nicht sind. Ergebnisse zum Gottesglauben sowie eine differenzierte Betrachtung der religiösen Selbsteinschätzung verdeutlichen, dass Annahmen einer Feminisierung von Religion weder vorschnell noch unreflektiert zu treffen sind. So hat bei männlichen Jugendlichen etwa der „Glauben an einen persönlichen Gott“ im Zeitverlauf bis 2006 zugenommen, und in der Frage nach der Existenz eines persönlichen Gottes ist der Unterschied zwischen den Geschlechtern geringer als in den beiden vorhergehenden Befragungswellen. ${ }^{65}$ Auch in der Jugend-Wertestudie 2011 lässt sich laut unveröffentlichtem Datensatz in der Überzeugung, dass es „einen leibhaftigen Gott" gibt, kein signifikanter Unterschied zwischen männlichen und weiblichen Jugendlichen feststellen. Weitere geschlechterindifferente Indikatoren finden sich bei den „christlichen Glaubensüberzeugungen“, in der „Bedeutungsfüllung von ,Spiritualität‘ und ,Esoterik““ sowie in der Einschätzung von „Kompetenzen, die der Kirche heute zugeschrieben werden“. ${ }^{66}$ Daher gilt, dass Mädchen zwar häufiger Religion praktizieren und Themen der Esoterik und Spiritualität offener gegenüberstehen, es wäre allerdings voreilig, „sie deshalb als religiöser zu bezeichnen; ihre Religiositäten lassen sich als körper-, gefühls-, und praxisnäher beschreiben". 67

\subsection{Kirchlich-konfessionelle Religionspraxis katholischer SchülerInnen}

Die folgenden Ausführungen beziehen sich auf die Projektstudie „Losing my religion. Religion - Glaube - Kirche bei 15-18jährigen Jugendlichen“, welche 2008 an oberösterreichischen Schulen im Rahmen des katholischen Religionsunterrichts durchgeführt wurde. ${ }^{68}$ Ein Interessenschwerpunkt lag dabei auf jener

62 Vgl. Polak 2008, S. 167 ff. und Heinzlmaier / Ikrath 2012, S. 39.

63 Vgl. Polak 2008, S. 168.

64 Vgl. Uhlik 2008, S. $170 \mathrm{ff}$.

65 Uhlik 2008, S. 177.

66 Ebd., S. 177.

67 Ebd., S. 175.

68 Methodisch handelt es sich um eine quantitative Online Untersuchung, bestehend 
Frage, ob die Kirche als institutionalisierte Form von Religiosität ein Ausdrucksort für Jugendliche ist, ihren Glauben zu leben; beziehungsweise ob Kirche ein Ort ist, wo sie Antworten auf ihre Fragen bekommen. Es zeigte sich, dass die SchülerInnen stärkeren Wert auf die Reformbedürftigkeit der katholischen Kirche legten (z. B. Einstellung zur Sexualität, Geschlechtergerechtigkeit, Umgang mit geschiedenen Wiederverheirateten, Zölibat). Für nur wenige ist Kirche der primäre Ort, wo Glaube gelebt werden kann; weder werden von der Mehrheit der befragten katholischen SchülerInnen traditionelle Glaubensinhalte und Riten als alltagsrelevant gesehen bzw. als Möglichkeit, Schwierigkeiten in ihrem Leben im Sinne des Oevermann'schen „Bewährungsmythos“ bewältigen zu können, noch sind Priester und SeelsorgerInnen die bevorzugten AnsprechpartnerInnen für Probleme. $^{69}$

\subsection{1. Über den Besuch von Gottesdiensten und dessen Motive}

Zwei Drittel (64,5 \%) der befragten Jugendlichen besuchen Gottesdienste, die Mehrheit davon $(63,7 \%)$ eher anlassbezogen, und zwar vorwiegend an bestimmten Feiertagen. Als Begründung für einen Gottesdienstbesuch äußern $38,8 \%$ ein eigenes Bedürfnis, wohingegen für 15,1 \% dem Wunsch anderer Personen, vorwiegend aus dem Familienkreis, folgen. Freiwilligkeit ist in diesem Punkt ein wichtiges Thema, Fremdbestimmung und Druck lässt Jugendliche den Kirchgang als unangenehme Pflicht erscheinen. Es werden auch Gründe genannt, wonach die Mitgestaltung ein Motiv ist oder die Jugendlichen im Rahmen des Schulgottesdienstbesuches oder in Verbindung mit anderen Vereinen in Kontakt zur Kirche kommen. Jene SchülerInnen, die keine Gottesdienste besuchen, begründen dies häufig damit, diese als langweilig und fad zu empfinden oder dass der Besuch zu früh am Morgen wäre. Nicht wenige erachten den Gottesdienst auch als eine „sinnlose Institution“ und „Religion nur etwas für Leute [...], die zu dumm sind, sich ihre eigene Meinung zu bilden“. ${ }^{70}$

\subsubsection{Kirchenbild}

Vor dem Hintergrund, dass Jugendliche etliche Elemente des Gottesdienstes als unzeitgemäß und überholt erachten, verwundert es kaum, dass sie ein ähnliches Kirchenbild ${ }^{71}$ zeichnen: Hier finden sich in den Antworten Aussagen wie: Die

aus 40 standardisierten Fragen, die z. T. Möglichkeiten für offene Antworten geboten haben. An der Umfrage nahmen 1554 SchülerInnen teil.

69 Dammayr 2010.

70 Ebd., S. 100.

71 Auch in der Shell Studie wurden die Jugendlichen zum Kirchenbild bzw. nach ihrer Einstellung zur Kirche befragt: $68 \%$ finden es gut, dass es die Kirche gibt, nur $27 \%$ würden sie nicht (mehr) brauchen. $68 \%$ sind jedoch auch der Meinung, sie müsste sich ändern, um eine Zukunft zu haben, $65 \%$ geben an, dass Kirche keine Antworten auf eigene Fragen und Lebensthemen zu geben vermag (vgl. Deutsche Shell 2006, S. 27). 
Kirche ist langweilig, fad, kalt, konservativ und altmodisch, aber auch still und ruhig. $^{72}$

Trotz dieses schlechten Image benennen die Jugendlichen Gründe, um in der Kirche zu sein: Bei den Angaben wird einerseits der pragmatische Umgang der Jugendlichen deutlich, insofern drei Viertel zugeben, ein Grund sei, später nicht auf eine kirchliche Trauung oder Beerdigung verzichten $\mathrm{zu}$ wollen (75,6\%). Andere Sakramente sind nur für $44 \%$ wichtig. Für 76,1 \% gilt Kirche als zur Kultur gehörig, und für 55,8 \% ist die Familie der Grund der Kirchenmitgliedschaft. Der Glaube bedeutet 50,2 \% viel, und die Kirche gibt 42,8 \% Sicherheit und Halt. In den offenen Antworten tritt der Gemeinschaftscharakter deutlich hervor, wenn es etwa heißt, dass „100\% Gemeinschaft und das Gefühl der Zugehörigkeit“, ebenso aber auch der „Zusammenhalt der Menschen und die gemeinsame Verbindung zu vielen Menschen "73 wichtig sind. Zudem werden als ein weiterer Grund die kirchlichen Feste genannt, „aber nicht, weil mir die Tage in religiöser Sicht wichtig sind, sondern weil ich die Bräuche und das Zusammensein mit meiner Familie genieße!!! “74

\subsubsection{Religiöse Praktiken und Rituale}

Bezüglich spezifisch religiöser Praktiken wie beten und Bibel lesen zeigen die Ergebnisse, dass ein eher geringer Prozentanteil zu diesen Bezug hat bzw. auf diese zurückgreift: So etwa geben $20 \%$ der SchülerInnen an, ,in schwierigen Zeiten meistens oder häufig zu beten“; ${ }^{75}$ deutlich weniger lesen in der Bibel: $82,6 \%$ geben bei dieser Frage an, dies nie zu tun. Einen Halt in für sie schwierigen Situationen suchen die jungen Menschen demnach weniger in religiösen Ritualen, ${ }^{76}$ sondern - wenig überraschend - bei ihren FreundInnen in der Peergruppe, was 88,6 \% bestätigen. Die Musik hat ebenfalls einen deutlich höheren Stellenwert wie auch die „Ablenkung“ durch Fernsehen oder PC. ${ }^{77}$ Vor diesem Hintergrund legt sich nunmehr die Vermutung nahe, dass Jugendliche weder in für sie schwierigen Situationen noch in ihrem Alltag der Religion eine hohe Bedeutung beimessen. Sie beziehen sich hingegen eher auf „funktionale Äquivalente“, die ihnen in bestimmten herausfordernden Situationen angemessener helfen. Als

\footnotetext{
72 Dammayr 2010, S. $134 \mathrm{f}$.

73 Ebd., S. 156f.

74 Ebd.

75 Der Blick wurde hier auf jene Fragen gelenkt, woher und woraus Heranwachsende ihre Kraft und ihren Mut nehmen, um prekäre Situationen zu meistern, was ihnen in solchen Phasen Halt gibt und welche Copingstrategien sie anwenden. Dabei interessierte, ob den jungen Menschen auch verschiedene religiöse Inhalte, Rituale und Praktiken zur Aufarbeitung von Konflikten, Problemen usw. eine Hilfestellung bieten.

76 Noch seltener als die bereits genannten Möglichkeiten gehen Jugendliche in für sie schwierigen Phasen in den Gottesdienst oder in die Kirche.

77 Vgl. ebd., S. 116f.
} 
eine Bewältigungsstrategie und im Sinne von „Bewährungsmythen“ greifen Jugendliche zunächst vorwiegend auf andere denn auf religiöse Unterstützungsstrukturen zurück.

Dass religiöse Praktiken jedoch auch nicht gänzlich abgelehnt werden - nur $31,0 \%$ geben an, überhaupt nie zu beten, und jeweils etwa $55 \%$ gehen nie in die Kirche oder in den Gottesdienst - lässt vermuten, dass Jugendliche auch aus diesem „Fundus“ schöpfen können und sich ihre Rituale dementsprechend ,aneignen". 78

Darauf verweisen auch die großen Feste im Jahreskreis, wie besonders Weihnachten und Ostern, die weiterhin einen festen Ort und Bedeutung im Leben der Jugendlichen einnehmen. So wird beispielsweise Weihnachten besonders als Fest der Familie und der Gemeinschaft empfunden, wird aber auch wegen der freien Zeit, der Geschenke und des Wintersports geschätzt. Demgegenüber liegen jedoch auch hier die eigentlichen religiösen Aspekte des Weihnachtsfestes ,,abgeschlagen" im Feld und haben im Vergleich zu anderen Zuschreibungen weniger Priorität: So trifft es für $17 \%$ voll und für weitere $31,2 \%$ eher zu, dass Weihnachten ,an die Geburt von Jesus erinnert““ ${ }^{79}$

\subsection{Untersuchungen zu muslimischen Jugendlichen in Österreich}

In Österreich ist der Islam seit 1912 als Religionsgesellschaft gesetzlich anerkannt und hat damit eine öffentlich-rechtliche Stellung. Auf institutioneller Ebene wurde diese Anerkennung 1979 durch die Gründung der „Islamischen Glaubensgemeinschaft in Österreich“ (IGGiÖ) ${ }^{80}$ konkretisiert.

Die Religiosität der europäischen Muslime bewegt sich zwischen Traditionalismus und Moderne und unterliegt einem Wandel. ${ }^{81}$ Adem Aygün kommt in seiner islamisch-religionspädagogischen Dissertation zum Ergebnis, dass muslimische Jugendliche empirisch heterogener als vergleichbare christlich-konfessionelle Gruppen sind und stabile Befunde, wie z. B. ein größerer Konservatismus, immer auch offengehalten werden müssen für die Vielfalt der islamisch-religiösen Identitäten. ${ }^{82}$ Nikola Tietze, die Formen muslimischer Religiosität junger Männer in Deutschland und Frankreich untersuchte, konnte feststellen, dass für Jugend-

\footnotetext{
78 Vgl. ebd., S. 116.

79 Ebd. S. $121 \mathrm{f}$.

80 Die IGGiÖ ist die exklusive Vertretung aller Muslime in Österreich gegenüber den staatlichen Behörden und hat auch eine vorrangige Stellung im Dialog mit der nichtmuslimischen Gesellschaft. Zum Vergleich besitzen die Muslime in Deutschland zwar ebenfalls das Recht auf individuelle wie kooperative Religionsfreiheit, allerdings existiert keine Körperschaft öffentlichen Rechts der Muslime.
}

81 Z. B. Sen / Aydin 2002.

82 Aygün 2013. 
liche Religion ein Teil der sozialen Identität sein kann, die sich auch mit Inhalten füllen lässt, die wenig mit der islamischen Doxa und den Traditionen zu tun haben (z. B. Hip-Hop Unterricht für Mädchen). Glaube (Believing) und Zugehörigkeit (Belonging) können sich ,auf vielfältige Weise verbinden, die sich der institutionellen Kontrolle zu entziehen scheinen; gleichzeitig schaffen die verschiedenen Ausdrucksformen muslimischer Religiosität Gleichgewichte zwischen believing und belonging und speisen sich aus der Tradition. [...] Die jungen Muslime arbeiten die religiöse Erinnerung um, damit sie sich in der Gesellschaft als muslimische Subjekte begreifen und behaupten können “. ${ }^{83}$ Ein signifikantes Ergebnis dieser Untersuchung ist: Auch der Islam und seine Institutionen müssen sich mit der Tatsache auseinandersetzen, dass ihre Macht zur Durchsetzung einer bestimmten religiösen Praxis und bestimmter Verhaltensweisen schwächer geworden ist. ${ }^{84}$

Für Österreich gilt ebenfalls, dass es unter den muslimischen Jugendlichen eine große Vielfalt des Umgangs mit dem Islam gibt und eine zunehmende Individualisierung von Religion deutlich wird. ${ }^{85} 2007$ erfasst Mouhanad Khorchide in einer qualitativ wie quantitativen Studie bei muslimischen Jugendlichen der zweiten Generation in Österreich die unterschiedlichen Bedeutungen des Islam im Rahmen einer mehrdimensionalen Typologie. ${ }^{86}$ Methodologisch orientiert er sich zunächst an drei der fünf Glock'schen Kerndimensionen der Religiosität (subjektive, rituelle und gesellschaftliche Dimension) und legt die Frage-Items in der subjektiven wie rituellen Dimension sehr strikt aus, um seine daran anschließende Typologie nachvollziehbar zu machen. So schreibt er in seiner Auswertung der subjektiven Religiosität („Der Islam spielt eine große Rolle in meinem Leben“) nur jenen eine starke Beziehung zum Islam zu, die in der vierskaligen Antwortmöglichkeit ${ }^{87}$ mit „trifft sehr zu“ (48\%) antworten. Allen anderen $52 \%$ (auch jenen $38 \%$, die bei „eher" ankreuzten) wird eine eher schwache Beziehung zum Islam bescheinigt. Er kann feststellen, dass sich die untersuchten Jugendlichen an kollektive Praktiken halten (wie z. B. das Fasten im Monat Ramadan), jedoch weniger an individuelle

83 Vgl. Tietze 2001, S. 78-85.

84 Ebd., S. 91.

85 Abu-Hamdeh 2012, S. 83.

86 Khorchide 2007, S. 217-242. Khorchide untersuchte jugendliche Muslime im Alter zwischen 16 und 26 Jahren, die entweder in Österreich geboren wurden oder vor dem 6. Lebensjahr eingewandert sind. Auf eine ausgewogene Relation zwischen weiblichen und männlichen Interviewpartnern wurde geachtet. Neben Jugendlichen aus der Türkei wurden auch solche aus Ex-Jugoslawien, dem arabischen Raum und dem Iran interviewt. Die quantitative Stichprobe umfasste 282 Jugendliche Wiens. In der qualitativen Untersuchung wurden 25 Jugendliche in unterschiedlichen Alltagskontexten (Jugendvereine, Moscheen, Lokale, Clubs, Diskotheken etc.) interviewt (vgl. Khorchide 2007, S. 223).

87 „trifft sehr zu“; , trifft eher zu“ „trifft eher nicht zu“ und „trifft gar nicht zu“. 
Praktiken (wie z. B. rituelle Gebete). Als streng praktizierend werden wiederum nur diejenigen bezeichnet, die alle Normen regelmäßig befolgen (19\%). Alle anderen $(81 \%)$ gelten als kaum praktizierend (bzw. gar nicht praktizierend). Die Einstellung der Zweiten Generation zur Gesellschaft wird durch mehrere Statements ermittelt, welche die nicht-muslimische Gesellschaft sozial ausgrenzen. ${ }^{88}$ Schwer fällt es nur $6 \%$ der befragten Jugendlichen, ${ }^{89}$ Menschen zu respektieren, die nicht Muslime sind und nur $4 \%$ distanzieren sich von ihnen; $5 \%$ meinen, dass ein Muslim nur Muslime als Freunde haben sollte, und $1 \%$ gab an, keine Freundschaft mit jemandem eingehen zu wollen, wenn dieser kein Muslim ist. Khorchide typologisiert in Folge sechs relevante bzw. auch zahlenmäßig unterscheidbare Gruppen (Fundamentalisten, Schalenmuslime, reflektierte Muslime, spirituelle Muslime, marginalisierte Distanzierte, assimilierte Distanzierte), die er auch anhand der Ergebnisse der qualitativen Gespräche mit den Jugendlichen näher erläutert: Fundamentalisten haben eine starke subjektive Beziehung zum Islam, befolgen streng die Rituale und Vorschriften, können aufgrund ihrer Auslegung der Religion nicht vorbehaltlos an der österreichischen Gesellschaft partizipieren und sind Andersgläubigen gegenüber negativ eingestellt (4\%). Eine schwächer fundamentalistische Position nehmen jene ein, die der österreichischen Gesellschaft „eingeschränkt offen" gegenüberstehen (7 \% ). Schalenmuslime werden jene Jugendlichen genannt, die sich ,reaktiv“ dem Islam annähern, um eine kollektive Identität (,Wir Muslime“) zu erlangen, aber kaum die Regeln des Islam praktizieren. Interaktionen mit der Mehrheitsgesellschaft werden abgelehnt (24\%). Reflektierte Muslime haben einen starken Bezug zum Islam, halten sich an Rituale und Vorschriften und stehen der österreichischen Gesellschaft offen gegenüber. Der Islam stellt für sie einen ethischen wie spirituellen Bezugsrahmen dar (7 \% ). Spirituelle Muslime sind jene, die sich trotz starker subjektiver Beziehung zum Islam kaum an seine Vorschriften und Praktiken halten. Sie partizipieren an der österreichischen Gesellschaft und stehen Andersgläubigen offen gegenüber (6\%). Marginalisierte Distanzierte stehen sowohl der Religion als auch der österreichischen Gesellschaft verschlossen oder nicht uneingeschränkt offen gegenüber (insgesamt $20 \%$ ). Den größten Anteil innerhalb dieser Typologie nehmen die assimilierten Distanzierten ein (31\%). Für sie spielt der Islam in ihrem Alltagsleben keine Rolle, und sie stehen der österreichischen Gesellschaft offen gegenüber. ${ }^{90}$

In der Geschlechterrollenverteilung nach den verschiedenen Religiositätstypen zeigt sich nicht unerwartet, dass eine patriarchalische Einstellung am stärksten vertreten ist bei den Fundamentalisten (23 \%) und den Schalenmuslimen (25\%). Die Hälfte (49 \% bzw. 50 \%) der distanzierten und assimilierten Muslime haben eine moderne und nur mit ca. $10 \%$ patriarchalische Einstellung. Reflektierte und Spirituelle haben am Häufigsten eine moderne Einstellung

88 Z. B.: „Es fällt mir schwer, Menschen, die nicht Muslime sind, zu respektieren.“ 89 Hier werden die Antworten „trifft sehr zu“ und „trifft eher zu“ addiert.

90 Vgl. Khorchide 2007, S. 223-231. 
(95\% bzw. $94 \%$ ), was anschaulich zeigt, dass eine reflektiert vollzogene $\mathrm{Zu}$ wendung zum Islam mit einer Distanzierung zu traditionellen Werten einhergehen kann. ${ }^{91}$

Die österreichische Jugend-Wertestudie $2006^{92}$ bestätigt, dass für Jugendliche mit Migrationshintergrund der Islam ein selbstverständlicher Bestandteil der Identität ist, unabhängig von Glauben und religiöser Praxis. Zudem kennen jugendliche Muslime und Musliminnen der zweiten und dritten Generation in Österreich den Unterschied zwischen Kultur und Religion und wissen, dass inhumane kulturelle Traditionen wie z. B. Zwangsheirat und Gewalt gegen Frauen religiös nicht zu begründen sind. Ihre Gottesbilder unterscheiden sich von jenen der österreichischen Jugendlichen ohne Migrationshintergrund: Mehr als die Hälfte steht zu Gott in Beziehung, glaubt, dass Gott einer ist, ,zu dem man beten kann“. An eine geistige Macht oder ein höheres Wesen glauben nur $18 \%$, und nur $4 \%$ glauben distanziert nicht an Gott. $80 \%$ glauben „,sehr“ oder „eher“, dass Gott sie liebt, und $65 \%$ sagen von sich selbst, eine innige Beziehung zu Gott zu haben.

\section{Zusammenfassung und Ausblick}

Abschließend lässt sich festhalten, dass sich hinsichtlich des Zusammenhangs von Jugend und Religion (auch) in Österreich Transformationsprozesse abzeichnen, wodurch sich ein vergleichsweise stärker plurales Bild ergibt als noch vor wenigen Jahrzehnten. Konnte man Mitte des letzten Jahrhunderts noch von einem katholischen Milieu sprechen, so weisen Ergebnisse der Jugendstudien darauf hin, dass das Verhältnis zu kirchlich-konfessionellen Religionsgemeinschaften und zu deren religiösen Sinnhorizonten und -angeboten zusehends brüchig wird und erodiert. Weiters finden sich für eine private religiöse Praxis, die kirchlich-konfessionell geprägt wäre, nur wenige Hinweise. Das lässt darauf schließen, dass in einer mehrheitlich immer noch christlich geprägten Gesellschaft weite Teile der Jugendlichen der Religion in ihrem Alltag keine prioritäre Bedeutung beimessen, wobei dennoch ein Bedürfnis nach Transzendenz bestehen bleibt. Durch das Zusammenbasteln, der „Bricolage“ verschiedenster Sinnelemente können sich in der Jugendphase „Selbsterfahrungsbausteine des Alltags“ zeigen, die „darin ihre religiöse, weil die eigene Existenz transzendierende Funktion bekommen“ “93

Ebenfalls heterogen sind Glaube und Religionspraxis muslimischer Jugendlicher. Sie erfahren die Differenz ihrer kulturellen Herkunft, fassen die Kultur und

91 Vgl. ebd., S. 238.

92 Vgl. Renner / Polak 2008, S. 188-203.

93 Feige 2010, S. 927. 
Religion ihrer Eltern mitunter als Identitätsmarker auf, ${ }^{94}$ und dennoch lässt sich auch bei ihnen eine zunehmende Individualisierung von Religion feststellen.

Die Prozesse der religiösen Ausdifferenzierung sind vielgestaltig, wodurch sich unterschiedliche „Einstellungs- und Verhaltensmuster“ zu Religion ergeben: Nicht wenige Jugendliche suchen (punktuell) in für sie lebensnahen und existenziell bedeutsamen Situationen durchaus Unterstützung und Orientierung im ihnen bekannten Religionsspektrum (z. B. in ihnen vertrauten Ritualen und Praktiken) und integrieren diese meist kreativ auf je eigene Weise in die eigene Biografie. Der gemeinschaftsstiftende Charakter von Religion ist nach wie vor ein zentrales Kriterium, das von Jugendlichen positiv konnotiert und geschätzt wird. Ebenso haben nicht wenige Jugendliche ein eher indifferentes Verhältnis zu Religion. Dies scheint auch für die Zukunft bedeutsam, denn ,[v]on der Frage nach dem Nicht-Glauben an Gott, bzw. des Verlustes des Gottesglaubens wird man weitere Differenzierungen erwarten können, man muss allerdings bedenken, dass auch diese Frage ein weites Spektrum einschließt, das von erklärtem und reflektiertem Atheismus, über einen praktischen Atheismus, über Agnostizimus bis hin zur religiösen Indifferenz reicht".${ }^{95}$

Insofern das Verhältnis von Jugend und Religion ein vergleichsweise eher geringer beforschtes Feld ist, ${ }^{96}$ scheint es für künftige Forschung besonders aufschlussreich zu sein, sowohl Phänomene von A-Religiosität, religiöser Indifferenz und Atheismus wie auch von Re-Traditionalisierung und Fundamentalismus stärker in den Blick zu bekommen, um erkennen zu können, in welchem Kontext derlei Entwicklungen stehen.

\section{Literaturverzeichnis}

Abu-Hamdeh, Tamara: Muslimische Jugendliche in Österreich. Untersuchung zur Religion. Diplomarbeit Universität Wien 2012.

Aygün, Adem: Religiöse Sozialisation und Entwicklung bei muslimischen Jugendlichen in Deutschland und in der Türkei: Empirische Analysen und religionspädagogische Herausforderungen. Münster 2013.

Barz, Heiner: Jugend und Religion. 3 Bände. Opladen 1992/93.

Beck, Ulrich: „Der eigene Gott“. Friedensfähigkeit und Gewaltpotential der Religionen. Frankfurt am Main 2008.

Berger, Peter L.: Zur Dialektik von Religion und Gesellschaft. Elemente einer soziologischen Theorie. Frankfurt am Main 1973.

Bertelsmann-Stiftung (Hg.): Religionsmonitor 2008. Gütersloh 2007.

Betz, Andrea / Ziebertz, Hans-Georg: „Tradition und Geschlechterrolle. Eine qualitative Studie unter christlichen und muslimischen Jungen“, in: Ziebertz, Hans-Georg

94 Betz / Ziebertz 2010.

95 Streib / Gennerich 2011, S. 111.

96 Vgl. Gründer / Scherr 2012, S. 64. 
(Hg.): Gender in Islam und Christentum. Theoretische und empirische Studien. Berlin 2010, S. 249-277.

Bucher, Rainer: „Entmonopolisierung und Machtverlust. Wie kam die Kirche in die Krise?“, in: Bucher, Rainer (Hg.): Die Provokation der Krise. Zwölf Fragen und Antworten zur Lage der Kirche. Würzburg 2005.

Bundeskanzleramt Österreich: Religionen in Österreich. Wien 2011.

Calmbach, Marc / Thomas, Peter M. / Borchard, Inga / Flaig, Bodo: Wie ticken Jugendliche? Lebenswelten von Jugendlichen im Alter von 14 bis 17 Jahren in Deutschland. Altenberg 2012.

Casanova, José: Public Religions in the Modern World. Chicago - London 1994.

Ders.: „Die religiöse Lage in Europa“, in: Joas, Hans / Wiegand, Klaus (Hg.): Säkularisierung und die Weltreligionen. Frankfurt 2007, S. 322-357.

Dammayr, Maria: „Losing my Religion...?“ Religion - Glaube - Kirche bei 15-18jährigen Jugendlichen. Ergebnisse einer empirischen Projektstudie in oberösterreichischen Schulen. Linz 2010.

Davie, Grace: Religion in Britain Since 1945: Believing without Belonging. Wiley 1994.

Demont, Oliver / Schenker, Dominik: Ansichten vom Göttlichen. 22 Jugendliche. Zürich 2009.

Denz, Hermann (Hg.): Die europäische Seele. Leben und Glauben in Europa. Wien 2002.

Deutsche Shell (Hg.): Jugend 2006. Eine pragmatische Generation unter Druck. Frankfurt am Main 2006.

Dies.: Jugend 2010. Eine pragmatische Generation behauptet sich. Frankfurt am Main 2010.

Englert, Rudolf: „Religiöse Bildung in Zeiten individualisierter Religiosität“, in: Englert, Rudolf / Schwab, Ulrich / Schweitzer, Friedrich / Ziebertz, Hans-Georg (Hg.): Welche Religionspädagogik ist pluralitätsfähig? Kontroversen um einen Leitbegriff. Freiburg im Breisgau 2012, S. 175-192.

Feige, Andreas: „Jugend und Religion“, in: Krüger, Heinz-Hermann / Grunert, Cathleen (Hg.): Handbuch der Kindheits- und Jugendforschung. Wiesbaden 2010, S. 917-931.

Ders.: „Die ,Religiosität‘ von Jugendlichen: Was ist eigentlich die Frage? Eine wissenssoziologische Analyse prototypischer empirischer Arbeiten und eine Skizze für ein theoretisch fundiertes Konzept empirischer Forschung“, in: Theo-Web. Zeitschrift für Religionspädagogik (11/1) 2012, S. 95-127.

Feige, Andreas / Gennerich, Carsten: Lebensorientierung Jugendlicher. Alltagsethik, Moral und Religion in der Wahrnehmung von Berufsschülerinnen und -schüler in Deutschland. Münster 2008.

Figl, Johann: „Säkularisierung“, in: Eicher, Peter (Hg.): Neues Handbuch theologischer Grundbegriffe. Bd. 4. München 2005, S. 72-80.

Forschungskonsortium WJT: Megaparty Glaubensfest. Weltjugendtag: Erlebnis - Medien - Organisation, hrsg. von Gebhardt, Winfried / Hitzler, Ronald / Liebl, Franz. Wiesbaden 2007.

Friesl, Christian (Hg.): Experiment Jung-Sein. Die Wertewelt österreichischer Jugendlicher. Wien 2001.

Friesl, Christian / Kromer, Ingrid / Polak, Regina (Hg.): Lieben - Leisten - Hoffen. Die Wertewelt junger Menschen in Österreich. Wien 2008. 
Gabriel, Karl: Christentum zwischen Tradition und Postmoderne. Freiburg im Breisgau 1992.

Ders.: „Säkularisierung und Wiederkehr der Religionen“, in: Kreutzer, Ansgar / Gruber, Franz (Hg.): Im Dialog. Systematische Theologie und Religionssoziologie. FreiburgBasel - Wien 2013, S. 267-277.

Gärtner, Christel: „Religiöse Identität und Wertbindungen von Jugendlichen in Deutschland“, in: KZfSS (53) 2013, S. 211-233.

Gebhardt, Winfried: „Believing without Belonging? Religiöse Individualisierung und neue Formen religiöser Vergemeinschaftung“, in: Kreutzer, Ansgar / Gruber, Franz (Hg.): Im Dialog. Systematische Theologie und Religionssoziologie. Freiburg - BaselWien 2013, S. 297-309.

Graf, Friedrich W.: Missbrauchte Götter. Zum Menschenbilderstreit in der Moderne. München 2009.

Gründer, René / Scherr, Albert: „Jugend und Religion. Soziologische Zugänge und Forschungsergebnisse“, in: Theo-Web. Zeitschrift für Religionspädagogik (11/1) 2012, S. 64-79.

Höhn, Hans-Joachim: „Soziologie in der Theologie“, in: Kreutzer, Ansgar / Gruber, Franz (Hg.): Im Dialog. Systematische Theologie und Religionssoziologie, a. a. O., S. $56-72$.

Husmann, Bärbel: Das Eigene finden. Eine qualitative Studie zur Religiosität Jugendlicher. Göttingen 2008.

Joas, Hans: Glaube als Option. Freiburg im Breisgau 2012.

Kaufmann, Franz-Xaver: Religion und Modernität. Sozialwissenschaftliche Perspektiven. Tübingen 1989.

Khorchide, Mouhanad: „Die Bedeutung des Islam für Muslime der zweiten Generation“, in: Weiss, Hildegard (Hg.): Leben in zwei Welten. Zur sozialen Integration ausländischer Jugendlicher der zweiten Generation. Wiesbaden 2007, S. 217-242.

Kizilkaya, Anakiz / El Hadad, Amr: Musliminnen und Muslime in Österreich. Bericht über die Lage der MuslimInnen in Österreich im Rahmen des Forschungsprojektes „Muslimische Milieus in Österreich“, hrsg. vom Institut für Bildungswissenschaft Fachbereich islamische Religionspädagogik der Universität Wien. Wien 2012.

Knoblauch, Hubert: Populäre Religion. Auf dem Weg in eine spirituelle Gesellschaft. Frankfurt am Main 2009.

Kögler, Ilse: „,Nun sag, wie hast du's mit der Religion?‘ am Beispiel jugendlicher Religiosität“, in: Österreichisches Religionspädagogisches Forum (22) 2014, S. 9-15.

Lukatis, Ingrid / Sommer, Regina / Wolf, Christof (Hg.): Religion und Geschlechterverhältnis. Opladen 2000.

Matthes, Joachim: „Auf der Suche nach dem ,Religiösen'. Reflexionen zu Theorie und Empirie religionssoziologischer Forschung“, in: Sociologia Internationalis (30) 1992, S. $129-142$.

Oevermann, Ulrich: „Strukturmodell von Religiosität“, in: Gabriel, Karl / Reuter, HansRichard (Hg.): Religion und Gesellschaft, Texte zur Religionssoziologie, in Zusammenarbeit mit Hermann-Josef Große Kracht, Wolfgang Marhold und Torsten Meireis. Paderborn u. a. 2004 [1996], S. 254-268.

Polak, Regina: Religion kehrt wieder. Handlungsoptionen in Kirche und Gesellschaft. Ostfildern 2006. 
Dies.: „Lebenshorizonte: Religion und Ethik“, in: Friesl, Christian / Kromer, Ingrid / Polak, Regina (Hg.): Lieben - Leisten - Hoffen. Die Wertewelt junger Menschen in Österreich. Wien 2008, S. 126-213.

Pollack, Detlef: Säkularisierung - ein moderner Mythos? Studien zum religiösen Wandel in Deutschland. Tübingen 2003.

Renner, Katharina / Polak, Regina: „Religiosität muslimischer Jugendlicher“, in: Friesl, Christian / Kromer, Ingrid / Polak, Regina (Hg.): Lieben - Leisten - Hoffen, a. a. O., S. 188-203.

Schröder, Bernd: „Die Religion der Schülerinnen und Schüler - Jugendkultur und Religionsunterricht", in: Wermke, Michael / Adam, Gottfried / Rothgangel, Martin (Hg.): Religion in der Sekundarstufe II. Ein Kompendium. Göttingen 2006, S. 146-166.

Sen, Faruk / Aydin, Hayrettin: Islam in Deutschland. München 2002.

Streib, Heinz / Gennerich, Carsten: Jugend und Religion. Bestandsaufnahmen, Analysen und Fallstudien zur Religiosität Jugendlicher. Weinheim - München 2011.

Thonak, Sylvia: Religion in der Jugendforschung. Eine kritische Analyse der Shell Jugendstudien in religionspädagogischer Absicht. Münster - Hamburg - London 2003.

Tietze, Nikola: Islamische Identitäten. Formen muslimischer Religiosität junger Männer in Deutschland und Frankreich. Hamburg 2001.

Uhlik, Julia: „Exemplarische Tiefenanalysen. Religiosität und Geschlecht“, in: Friesl, Christian / Kromer, Ingrid / Polak, Regina (Hg.): Lieben - Leisten - Hoffen, a.a.O., S. 169-182.

Verhülsdonk, Andreas: „Ist der konfessionelle Religionsunterricht pluralitätsfähig ?“, in: Englert, Rudolf / Schwab, Ulrich / Schweitzer, Friedrich / Ziebertz, Hans-Georg (Hg.): Welche Religionspädagogik ist pluralitätsfähig? a.a.O., S. 15-27.

Woodhead, Linda: „Gendering Secularization Theory“, in: Social Compass (55/2) 2008, S. 187-193.

Ziebertz, Hans-Georg / Hermans, Chris / Riegel, Ulrich: „Interkulturalität, Identität und Religion“, in: Ziebertz, Hans-Georg (Hg.): Gender in Islam und Christentum. Theoretische und empirische Studien. Berlin 2010, S. 79-92.

Ziebertz, Hans-Georg / Riegel, Ulrich: Letzte Sicherheiten. Eine empirische Untersuchung zu Weltbildern Jugendlicher. Gütersloh 2008.

\section{Internetquellen}

Heinzlmaier, Bernhard / Ikrath, Philipp: Bericht zur Jugendwertestudie 2011, Wien 2012, verfügbar unter: http://jugendkultur.at/wpcontent/uploads/Bericht_Jugendwertestu die_2011.pdf [12.12.2013].

Katholische Kirche Österreich (o. J.): Statistik, verfügbar unter: http://www.katholisch.at/ statistik [29.01.2014].

Statistik Austria (2007): Bevölkerung nach dem Religionsbekenntnis und Bundesländern 1951 bis 2001, 2007, verfügbar unter: http://www.statistik.at/web_de/statistiken/be voelkerung/volkszaehlungen_registerzaehlungen/bevoelkerung_nach_demographisc hen_merkmalen/022885.html [29.01.2014]. 
Dies.: Bevölkerung Österreichs seit 1869 nach Bundesländern, 2013a, verfügbar unter: http://www.statistik.at/web_de/statistiken/bevoelkerung/volkszaehlungen_registerza ehlungen/bevoelkerungsstand/023290.html [29.01.2014].

Dies.: Bevölkerung mit Migrationshintergrund seit 2008, 2013b, verfügbar unter: http:// www.statistik.at/web_de/statistiken/bevoelkerung/bevoelkerungsstruktur/bevoelker ung_nach_migrationshintergrund/069443.html [29.01.2014]. 